\title{
THE PLACE OF VENEREAL DISEASE IN THE MEDICAL CURRICULUM*
}

\author{
By J. H. SEQUEIRA, F.R.C.P., F.R C.S.
}

DR. Wilfrid Fox, Ladies and Gentlemen,-When your Secretary asked me to address the Society I thought I could not do better than raise the question of the teaching of venereal disease in the medical schools. I did not anticipate that the subject would be alluded to in the address of the President at Cambridge, and trust that the presentation of the problems at issue from another point of view may lead to a useful discussion.

I may, perhaps, appear to be deliberately provocative in some of my remarks, but I venture to claim that my intentions are good, and that my only interest in the subject is the welfare of the community. I believe strongly that the best investment for the country in the combat against venereal disease, and especially against syphilis, is a high standard of knowledge throughout the profession. My object to-night is to ask you to consider with me how that laudable consummation can be attained.

It will, I think, be convenient if we pause for a few moments to study the past, not as you might expect from one so senior as myself, in the spirit of the laudator temporis acti, but as a study in evolution.

In my early days, both as student, resident and on the staff of my hospital, it was the custom everywhere for the surgeons to deal with the venereal diseases in their initial stages. It was in the surgical out-patient department that we were taught the differential diagnosis of the primary lesions of syphilis as they affected the genital organs, the distinguishing characters of the ulcus molle, and some surgeons-not all-paid attention to blenorrhagia and its complications. The surgeon also dealt with the secondary manifestations of syphilis and gummata so far as they involved accessible regions. The

* Based upon an Address delivared to the Medica Society for the Study of Venereal Diseases on March 25th, 1927. 
result was, on the whole, satisfactory. The majority of the men who had spent six months in the out-patient surgical clinics went out into practice with a fair knowledge of the diagnosis and treatment of the early, and many of the late, manifestations of the spironemal infection.

In the ophthalmic department the surgeon in charge gave instruction in the diagnosis and treatment of the congenital and acquired affections of the eye. The department of dermatology also took a share in the instruction. It was here that the physician in charge taught the differential diagnosis between the eruptions of both acquired and congenital syphilis, and the numerous affections which they closely simulate. In the skin clinic the student learnt how to distinguish the macular syphilide from pityriasis rosea, and the differences between lichen planus, psoriasis and the seborrhoides from the group of papulo-squamous syphilides. He was taught to use his eyes, and in so doing in a few months was able to solve many of the diagnostic problems presented by the cutaneous syphilides. But there was no compulsory attendance in the skin department, and it is impossible to deny that a large proportion of men leaving the hospitals had a very slight acquaintance with the commoner skin eruptions. As the Report of the Royal Commission of I9I3 pointed out, the average practitioner was insufficiently instructed in the diagnosis and treatment of venereal disease in its earlier stages.

You will notice that throughout this period the general physician stood sublimely aloof from the more sordid aspects of syphilis. He only began to take interest in the results of spironemal infection when they had already gravely threatened the patient's life, and often not until they were incurable. The exact phenomena associated with aortic disease and aneurysm were all carefully drilled into the student, who was encouraged to verify his observations in the post-mortem room. The involvement of the tracts of the spinal cord and the localisation of gummata and other inflammatory reactions in the brain and viscera presented intricate problems which afforded the philosophical physician fields for study and investigation. The accuracy of the diagnosis was only too frequently confirmed in the department of morbid anatomy. As the late Sir James MacKenzie truly observed, the 


\section{BRITISH JOURNAL OF VENEREAL DISEASES}

" end results " of disease bulked largely into the student's curriculum.

Now we come to a critical year-IgI3. The great International Congress is due-a letter from Sir Malcolm Morris on the venereal peril appears in the medical Press-it is followed by others-a great wave of propaganda starts. The lay Press throws aside its reluctance to deal with an unsavoury subject. The Congress meets and the Government are called upon to do something to relieve the menace. A reluctant Premier agrees to a Royal Commission under the chairmanship of Lord Sydenham of Combe. Evidence is taken, and among the recommendations made is one that steps should be taken to improve the education of medical men in the diagnosis and treatment of venereal disease.

Before the Report of the Royal Commission was issued my former colleague, Mr. Frank Kidd, had established and developed the treatment of gonorrhœa on modern lines in the Genito-Urinary Clinic at the London Hospital, and I had arranged with my colleagues that the treatment of syphilis in its early stages should be dealt with in the Skin Department.

Both in the Genito-Urinary Department and the Skin Department of the London Hospital there was organised instruction in the modern diagnosis and treatment of the two major venereal diseases. In making these departures we anticipated the recommendation of the Royal Commission, and our departments had been equipped both for treatment and for instruction long before Mr. Walter Long, then the President of the Local Government Board, introduced his Bill.

An ideal course on syphilis would comprise contributions from the bacteriologist, serologist and pathologist, with lectures and demonstrations from the dermatologist, general physician and surgeon, neurologist, ophthalmologist, and laryngologist. Such a course for post-graduation and senior students, consisting of twenty-four lectures and demonstrations, was given in the early part of I9I4 by the staff of the London Hospital. The experiment was a great success, but it was not repeated owing to the war. The post-war arrangements for teaching in the schools and the establishment of this Society appeared to fulfil the demands both of the senior student and the post-graduate. 


\section{VENEREAL DISEASE : MEDICAL CURRICULUM}

We now come to the inauguration of a special service to deal with venereal disease, and its first objective was to cope with the great increase in the incidence of those affections due to the war. More and more clinics were opened, and it seemed a happy coincidence that at that period a large number of men who had had experience in V.D. in the Services were set free to take up this work in the civil community. The qualifications of these venereal specialists were being examined at the request of the Army Medical Department by a small committee, of which I was a member, but this work ceased at the Armistice, and the incomplete report is, no doubt, mercifully pigeonholed at Whitehall.

I presume that we all agree that the practitioner, on becoming qualified, should be able to diagnose at sight a straightforward case of primary or secondary syphilis, that he should be able to take blood for the Wassermann test or a specimen of serum to send to the laboratory. He should be shown diagnosis by dark background illumination. But I do not think we can expect many men to give a satisfactory diagnosis by this means after they have left hospital for any length of time. Also, they should learn the technique of intravenous injection and the dangers and complications attending it.

Everyone admires Colonel Harrison's heroic efforts to make every general practitioner a venereal expert, but even his text-book, and the detailed instruction and expensive apparatus described, are not applicable to many general practices.

In suspected gonorrhœa the student must learn to take the necessary specimen for the laboratory, and he must be taught the modern methods of treatment; though it seems advisable that there should be care taken to check that wholesale irrigation which swells the number of attendances in the clinics and, I am credibly informed, helps materially the birth control movement by its effects on the posterior urethra.

\section{State-Aided Clinics and the Instruction OF STUDENTS}

Personally, I see no reason why there should be any question as to the necessity and advisability of using the clinics which are supported by the State and local 
authorities for the teaching of students. But in practice difficulties present themselves, and these must be faced.

In proof of this I would like to recall the following incident: Not long ago the members of the staff responsible for V.D. treatment at a certain hospital met in consultation gentlemen representing the public bodies concerned for the purpose of discussing certain developments requiring the outlay of money. The medical representatives were specially warned before the meeting that on no account should the question of teaching facilities be brought into the discussion; in other words, that if the education of future medical practitioners were introduced, the scheme for which financial support was desired would fall through. Whether this attitude applied to the Sanitats-Rat who was present or only to the non-medical members of the body concerned did not transpire. I mention it as indicating a point of view.

Again, one of the gentlemen who was kind enough to answer my questionnaire mentions that, by agreement with the officials of the financing bodies, the medical officers do not give long demonstrations which would suggest to the patients that they are teaching students, and, moreover, that the students who are clerking in the V.D. Departments are given the honorary title of " clinical assistant," which is, of course, usually applied to a qualified officer.

These are merely examples which are, I think, significant. Why should there be this atmosphere of dissimulation?

My second point is that to instruct students there must be adequate opportunity. This can only be obtained by a sufficiency of cases. We are told on good authority that the number of patients attending a clinic depends largely on the way that clinic is advertised. Sufferers from Southend or Surbiton are told of the amenities which are to be found at the clinic of the X or Y Hospital, and consequently flock there. Surely the great medical schools should have the preference, because only in them can the greatest number of medical practitioners be taught, and all should be run on equal terms. Here, again, we find some curiosities. Our clinic is advertised as having over Io,000 venereal cases in a year. As a matter of fact, this number was for total attendances. The total number of new cases was just over 400-about 


\section{VENEREAL DISEASE: MEDICAL CURRICULUM}

eight a week - a poor supply of patients for the teaching of V.D. in a large medical school.

Is it proposed to teach V.D. at certain centres, like the fever hospitals of the Metropolitan Asylums Board ? I earnestly hope not. The student's curriculum is already over full, and it would be disastrous to increase it.

The Deans of the medical schools in London, the provinces, and Scotland have supplied me with a mass of interesting material, which I summarise briefly here.

\section{Time}

The time allotted in the schools for attendance in the V.D. Clinics is usually three months. Some schools require an attendance at twelve demonstrations. Although the teaching is mainly clinical, courses of lectures are given in many instances varying from two on syphilis and two on gonorrhœa in one instance to ten lectures in others.

As a rule, attendance is now compulsory before a student presents himself for his final examination, but at one school attendance is still optional, although I understand this is to be changed in the near future. Opinion appears to vary considerably as to the most appropriate time for the student to attend the courses. In two schools the second clinical year is selected. In other cases the period of in-patient clerking and dressing is specifically chosen; but in the majority the fifth or final year is preferred, often in conjunction with attendance in the skin and other special departments.

\section{CONCLUSIONS}

For my own part, I wish that for venereal diseases as such there were no place in the student's curriculum. I would insist on adequate instruction in the diagnosis and treatment of syphilis in all its stages. I still hold that the student is best taught the diagnosis and treatment of the primary stage and of the cutaneous manifestations, both of the acquired and congenital forms, in the skin department. I maintain that for the patient this is also an advantage, especially as a large proportion of the women and all the children are unfairly labelled as V.D. cases. Eye, ear, throat, nervous and visceral affec- 


\section{BRITISH JOURNAL OF VENEREAL DISEASES}

tions are möre appropriately taught in their respective departments than in a special venereal clinic.

There should also be adequate instruction in the diagnosis and treatment of gonorrhœea. A large proportion of the patients who attend a V.D. Department are not gonococcal, particularly among the females. Surely these are better dealt with in a G.-U. or Gynæcological Department. If for administrative purposes nothing better can be proposed than the making of ad hoc clinics, I would urge that the heads of these departments should be part-time officers with a wide outlook. I should make my choice among the younger members of the staff of a teaching hospital. They should be able to teach, and should not be afraid of teaching, not only diagnosis and treatment, but also preventive measures. Nothing, I think, could be worse for the future than the production of a class of V.D. specialists locked up in their own narrow sphere, whose efficiency is gauged by the increasing number of attendances, absence of complaints, and by the optimism of reports which can be incorporated in the annual review presented to local authorities and to Whitehall. We want to avoid that type of obedience to authority which,

" Bare of all genius, virtue, freedom, truth, Makes slaves of men, and of the human frame A mechanised automaton." 